\title{
Application, validation and comparison in different geographical contexts of an integrated model for the design of ecological networks
}

\author{
C.R. Fichera, ${ }^{1}$ R. Gianoglio, ${ }^{2}$ L. Laudari, ${ }^{1}$ G. Modica ${ }^{1}$ \\ 'Dipartimento di Agraria, Università degli studi Mediterranea di Reggio Calabria. Località Feo di \\ Vito, Reggio Calabria, Italy; ${ }^{2}$ Seacoop arl, Torino, Italy
}

\begin{abstract}
The issue of the fragmentation of natural habitats is increasingly at the core of the scientific debate, yet it is not taken into account in planning tools, with particular reference to the dynamism and complexity of landscapes. As it has been recognised at a European level, in order to enable different species to remain in good functional status, a network of green infrastructures is required. The concept of "ecological island" is no longer sufficient to adequately protect the fauna and the ecosystem it lives in. As a consequence, ecological islands must turn into ecological networks. The Ecological connectivity refers to the way habitats are physically connected to each other and how easy it is for species to move in. Good ecological connectivity is fundamental to the effective conservation of biodiversity considering that most species and ecological functions provided by ecosystems (ecosystem services) require a much wider space than that available within the boundaries of a single protected area. The main objective of this paper is to critically compare the application of a model for the design of ecological networks to two very different environmental contexts. This model was first tested in a Mediterranean area (the Province of Reggio Calabria) in 2008; the goal was to integrate the traditional (physiographic and functional) approaches into the design of ecological networks by taking into account biological and orographic elements as well as the anthropic structure of the territory. In 2011, within the ECONNECT European project, the model was applied to the pilot region of South-Western Alps (including the French region of Provence-Alpes - Côte d'Azur and the Italian regions Piedmont and Liguria), which is one of the richest transnational districts in Europe in terms of biodiversity. In such a region, the issue of multidisciplinary ecological connectivity was tackled in order to provide a series of proposals aiming at the development of the ecological potential of the
\end{abstract}

Correspondence: Luigi Laudari, Dipartimento di Agraria, Università degli studi Mediterranea di Reggio Calabria, Località Feo di Vito, 89122 Reggio Calabria, Italy.

E-mail: luigi.audari@unirc.it

Key words: ecological networks design, ecological connectivity, geographical information systems, sustainable planning.

@C Copyright C.R. Fichera et al., 2013

Licensee PAGEPress, Italy

Journal of Agricultural Engineering 2013; XLIV(s2):e98

doi:10.4081/jae.2013.s2.e98

This article is distributed under the terms of the Creative Commons Attribution Noncommercial License (by-nc 3.0) which permits any noncommercial use, distribution, and reproduction in any medium, provided the original author(s) and source are credited. area. The two applications allowed to further investigate the strengths and weaknesses of the implemented model by integrating its validation with information on faunal presence, which obviated one of the major limitations occurred in the first application.

\section{Introduction}

Over the last decade, the concept of ecological network has increasingly established itself in the European technical and scientific scenario (Rientjes \& Roumelioti, 2003). Nevertheless, the term "ecological network" is not defined univocally and it is subject to different interpretations (Boitani, Falcucci, Maiorano, \& Rondinini, 2007).

A first widely recognised approach is the structural (physiographic) one, which is based on the patch-matrix-corridor paradigm (Godron \& Forman, 1983) where an ecological network is simplified in landscape morphological elements, such as core areas, corridors and buffer zones (R. Jongman \& Pungetti, 2004). This interpretation derives from the assumption that the ecological management of the environmental mosaic should be investigated in an integrated manner and considering various space and time scales. Later on, this led to the concept of Multiple-Use Modules (MUM) (Noss \& Harris, 1986) and to the use of the structural approach to define networks of habitats (Hobbs, 2002) (e.g. the Natura 2000 network, the centerpiece of EU nature and biodiversity policy).

A second widespread approach is the functional one, where the elements of the ecological network are interpreted as a whole of ecosystems (core areas) connected through channels of functional relationships between the organisms of the ecosystem (Opdam, Steingröver, \& Rooij, 2006). These differences in interpretations are one of the major problems concerning the technical and operational proposals aimed at the definition of ecological networks (Rientjes \& Roumelioti, 2003). Actually, this was the theoretical and operational starting point of this research work, which aims at identifying a method that may integrate the above-mentioned approaches obviating the need of detailed spatialized bio-ecological observations that are not often available or based on reliable time and space data. Yet, at the same time, such a method should not lead to the mere identification of physical constituent elements but to a procedure with clear impacts on sustainable spatial planning at a medium and small scale.

In particular, a model for the definition of an ecological network as a guideline in the planning process (Fichera, Laudari, \& Modica, 2009a, 2009b) was implemented within a wider research activity carried out by the authors to define models of sustainable landscape planning which take into account ecological connectivity (Fichera, Laudari, $\&$ Modica, 2007). From a methodological point of view, the developed model is composed of a system of algorithms operating on a specially structured and implemented geodatabase in a dedicated GIS that, through repeated processing of habitat quality and definitions of core areas, is able to determine the organization of the ecology connectivity 
matrix. The model combines the two classical approaches for the definition of ecological networks and sets out an integrated ecological network that corresponds to the real territorial structure and actual ecological needs. The model was applied to the territory of the province of Reggio Calabria (Italy) emphasizing its potentials and limitations as a guiding tool for a sustainable land-use planning (Fichera, Laudari, \& Modica, 2010).

The resulting network design allows obtaining spatial continuity functional to faunal dispersion without any excessive impact on the study area. Data inputs were implemented on a FunConn (Functional Connectivity) model (Theobald, Norman, \& Sherburne, 2006). Such a model, which provides graph-theory based analysis methods for landscape connectivity, was modified and adapted for its application to the specific areas.

\section{Materials and methods}

\section{Study area}

Within the "Alpine Space Programme" (ETC - European Territorial Cooperation, 2007), the European Union has launched the project ECONNECT with the purpose of implementing an ecological continuum across the alpine region over the three years 2008/2011. The main goal of the project is to increase the ecological connectivity of the Alps through a holistic and multidisciplinary approach based on a model that is centred on the qualitative and quantitative selection of the areas of significant ecological value and on the analysis of their levels of interconnection.

In order to achieve that goal, the workgroup, which was entrusted with the implementation of the project in the Alps South-West pilot region (one of the seven ECONNECT regions which are evenly distributed throughout the Alps), adopted the model for the design of ecological networks that (Fichera, Laudari, \& Modica, 2009c) had elaborated by adapting and modifying the FunConn model.
This opportunity allowed comparing the design of two ecological networks obtained with the same model applied to territorial contexts (Figure 1) that are deeply different from the administrative, bioecological and geographical point of view:

- The Province of Reggio Calabria, which belongs to the Mediterranean biogeographical region;

- The side of the Maritime Alps that is part of the Province of Cuneo and belongs to the alpine biogeographical region.

\section{Comparison of the model in the two different geographical contexts}

The research work was organized in distinct and consequential steps that were carried out at the same time in the two study areas:

Definition of the integrated ecological networks on the two areas;

Selection of common indicators for the context analysis;

Comparison of the two ecological networks.

Ecological networks were elaborated in the two following steps (Figure 2):

- In the first step, a specific ecological network was elaborated for each focal species found in the study areas (Battisti \& Luiselli, 2011; Boitani, 2000; Watts et al., 2010). This allowed identifying specific core areas and their related corridors (Bennet \& Wit, 2001; Bennett \& Mulongoy, 2006).

- In the second step, after identifying the portions of core areas of greatest ecological importance through overlay mapping, the specific ecological networks were aggregated to the "institutional" core areas found in the study areas (Kunzl et al., 2011). The resulting configuration corresponded to the main design of the core areas of the integrated ecological network. Starting from such core areas, the model was used again to calculate the corridors, which, in this network, are plurispecific transit areas.

In this first phase, a difference in the application of the model to the two study areas should be highlighted. In fact, while the identification of the core areas in the Province of Reggio Calabria took into account Park's Integral Reserves, SCIs (92/43/CEE) and SPAs (79/409/CEE) of

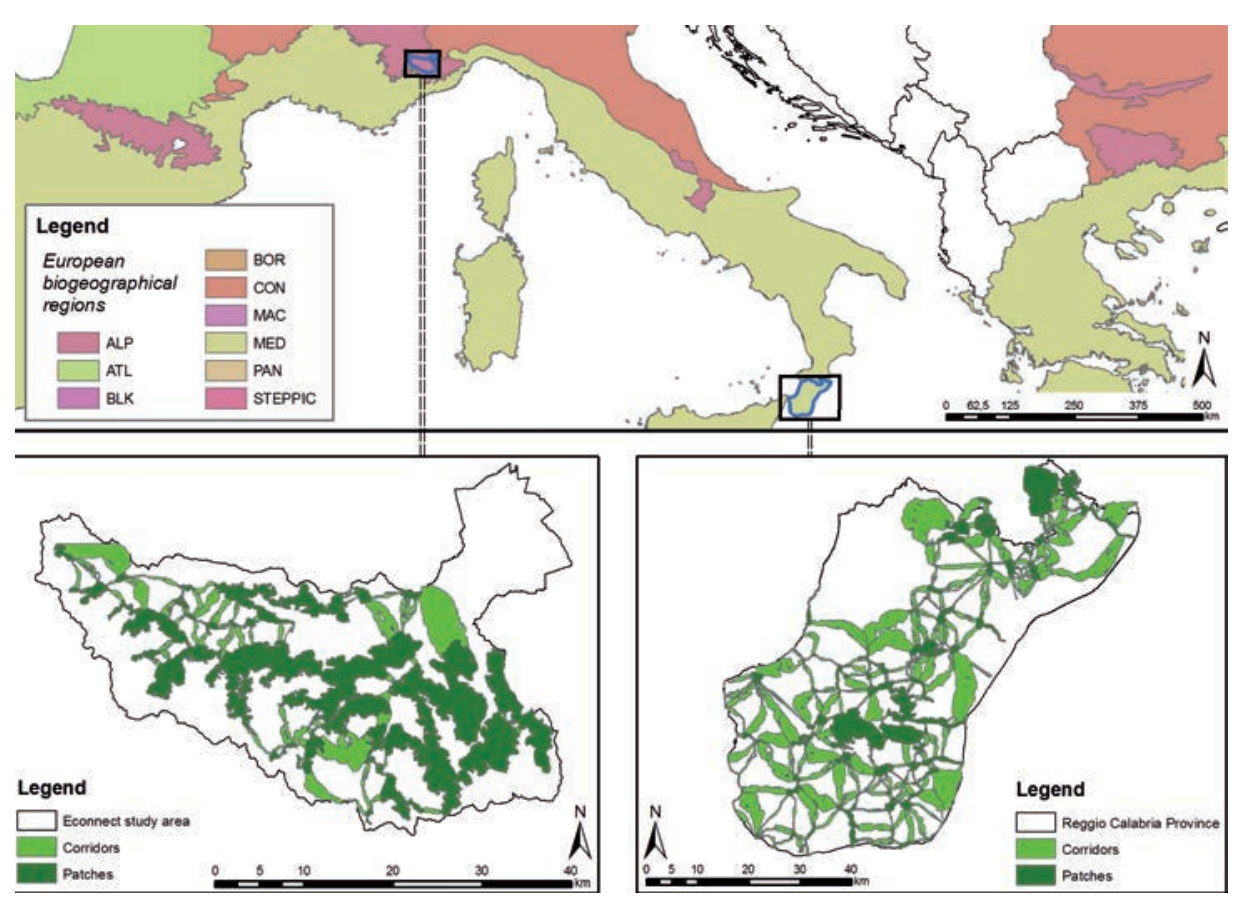

Figure 1. Location of the study areas in their European Biogeographical Regions and organization of the two ecological networks. 
the Natura 2000 network (Boitani et al., 2007), in the case of the Maritime Alps, Integral Natural Reserves and Special Natural Reserves (areas of great natural value defined by the Regione Piemonte) were considered. However, this choice was suggested by objective reflections: actually, in the Piedmontese study area, the Natura 2000 system is particularly extended and not completely differentiated according to specific ecological needs. Therefore, it appears as a continuum of protected areas which would make any resulting ecological network, made up of short corridors, completely useless.

The indicators for the network analysis were selected by referring to four indexes which had already been adopted in previous studies (Fichera et al., 2009b) to validate the networks obtained through various methodological approaches (Bennett \& Mulongoy, 2006; Boitani et al., 2007; Franco, 2003; R. H. G. Jongman, 1995; Mortelliti, Amori, \& Boitani, 2010):

Biopermeability: the ease with which an animal organism can cross a territory with certain environmental characteristics (APAT, 2003; Fiduccia, 1998; Romano, 2000).

- Anthropic disturbance: the impact generated by population density and vehicular load per road class section (Forman 2000).

- Landscape Fragmentation: level of territorial destructuring caused by the interference of anthropic activity (Jaeger, 2000; Romano, 2003, 2005).

Environmental sustainability Index (ESI): an indicator of ecological stability determined by the balance of pressure effects and by the regeneration potential typical of each territorial typological unit (Magoni, M. Steiner, 2001).

The values of the indicators were grouped into classes according to their similar impact and the results obtained were shown separately for each of them in the following graphs and figures.

\section{Discussion of results}

\section{Landscape biopermeability index (LBI)}

The landscape biopermeability index (Bona, Badino, \& Isaia, 2006) was obtained by reclassifying the codes of the Corine Land Cover Map (EEA (European Environment Agency), 2000) and assigning a permeability value to each class. Such values were obtained by averaging those found in the literature (Drielsma, Ferrier, \& Manion, 2007; Fiduccia, 1998; Metzger \& Dècamps, 1997; Romano, 2000), which are strictly linked to the habitat preferences in terms of land-use categories of the focal species and ability of focal species in crossing a certain land-use category (Pelorosso et al., 2008).

The spatial representation of this index can be defined as a map illustrating the ability of focal species to pass through or to adapt to a given vegetational or land-use category (Bona et al., 2006). A biopermeability map was created for each study area and the portions of the two ecological networks were extracted from each map (Figure 3 ). The surface values of biopermeability were grouped into four classes and were made comparable through the calculation of their incidence rates (Figure 4).

As the graph shows, the landscape biopermeability index has a similar trend in the study areas and in the corresponding ecological networks, which expresses a clear improvement in the conditions of biopermeability within the territories of the ecological networks in comparison with the overall surfaces of the study areas.

\section{Anthropic disturbance index (ADI)}

The Anthropic disturbance index was obtained by integrating the urban area map and the road network map. Both maps were classified

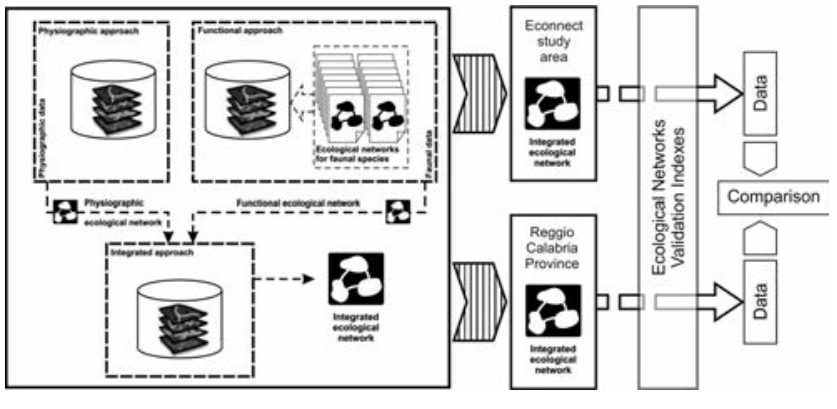

Figure 2. Diagram of the general model and flow chart of the analysis and comparison operations.

in relation to population density and potential vehicular load per road section (Forman \& Alexander, 1998) within the land cover map. The resulting values allowed measuring the variation in the disturbance effect as the distance from the source increased (Forman, 2003).

The cartography highlighted the spread of anthropic disturbance phenomena on the examined territories. An anthropic disturbance map was created for each study area and the portions of the two ecological networks were extracted from each map (Figure 5). The surface values of anthropic disturbance were grouped into four classes and made comparable through the calculation of the relative incidence rates (Figure 6).

In this case, the graph shows a trend that does not perfectly coincide with the index spatial distribution on the study areas as well as a certain difference, between the ECONNECT study area and its ecological network, in the land cover rates of the third disturbance class. This discrepancy is due to the composition of the territorial mosaic (Forman, 2008) of this area, which has neither infrastructures with high disturbance level nor areas with urbanization density that compares with the Province of Reggio Calabria.

\section{Landscape fragmentation Index (LFI)}

Sprawl phenomena show that anthropic expansion (Forman, 2008; Harris, 1984; Saunders, Hobbs, \& Margules, 1991) has led to a remarkable qualitative and quantitative reduction in rural areas (Modica et al., 2012) with consequent ecosystemic changes caused by the progressive isolation of the residual natural areas and the interruption of the ecological connections existing between spatially separate landscape elements (Haber, 1993).

The index adopted to measure this phenomenon integrates three territorial parameters:

- The level of organization of biopermeable areas, which is useful to identify situations characterized by high spatial variability in land use and, therefore, by a well-organized environmental mosaic (Forman, 2008):

$$
\text { Tbiop }=\sum \text { Abiop } / A u
$$

Where: Abiop indicates biopermeable areas and $A u$ is the area of the reference territorial unit.

- The urbanization density index (Romano, 2003, 2005), which was adopted to measure the built area per reference unit:

$$
D U u=\sum A u r b / A u
$$

Where: Aurb indicates the urbanized areas and $A u$ is the area of the reference territorial unit. 
- Infrastructure-related fragmentation index (Romano, 2003, 2005), which measures the density of the road network that is diversified according to the level of congestion:

$$
I F I=\sum l_{i} * o_{i} / A u
$$

Where: $l_{i}$ is the length of the single road sections, $o_{i}$ is the congestion coefficient of each type of road (in percent values) and $A u$ is the area of the reference territorial unit.

Once such parameters were mapped and displayed using simple overlay map types, nine landscape fragmentation classes were derived from them (Table 1).

A landscape fragmentation index map was created for each study area and its ecological networks (Figure 7). The corresponding surface values were grouped into four classes and made comparable through the calculation of their incidence rates (Figure 8).

The graph shows a similar trend of the values of the indicator for the two study areas and for the two ecological networks. The variation observed in the III (F and G) and IV (H and I) classes is due to the weak urban dominance of the ECONNECT study area.
Table 1. Landscape Fragmentation Index (LFI) types

\begin{tabular}{lc} 
Classes & Description of the characteristics \\
A & Very high fragmentation with agricultural hyper-dominance \\
B & High fragmentation with urban hyper-dominance \\
\hline C & High fragmentation with urban dominance \\
D & $\begin{array}{c}\text { High fragmentation with agricultural dominance } \\
\text { and strong infrastructural sub-dominance }\end{array}$ \\
\hline E & $\begin{array}{c}\text { High fragmentation with agricultural dominance } \\
\text { and weak infrastructural sub-dominance }\end{array}$ \\
F & Average fragmentation with urban dominance \\
\hline G & Average fragmentation with agricultural dominance \\
H & Low fragmentation with high urban dominance \\
\hline I & Very low fragmentation with weak urban dominance \\
\hline
\end{tabular}
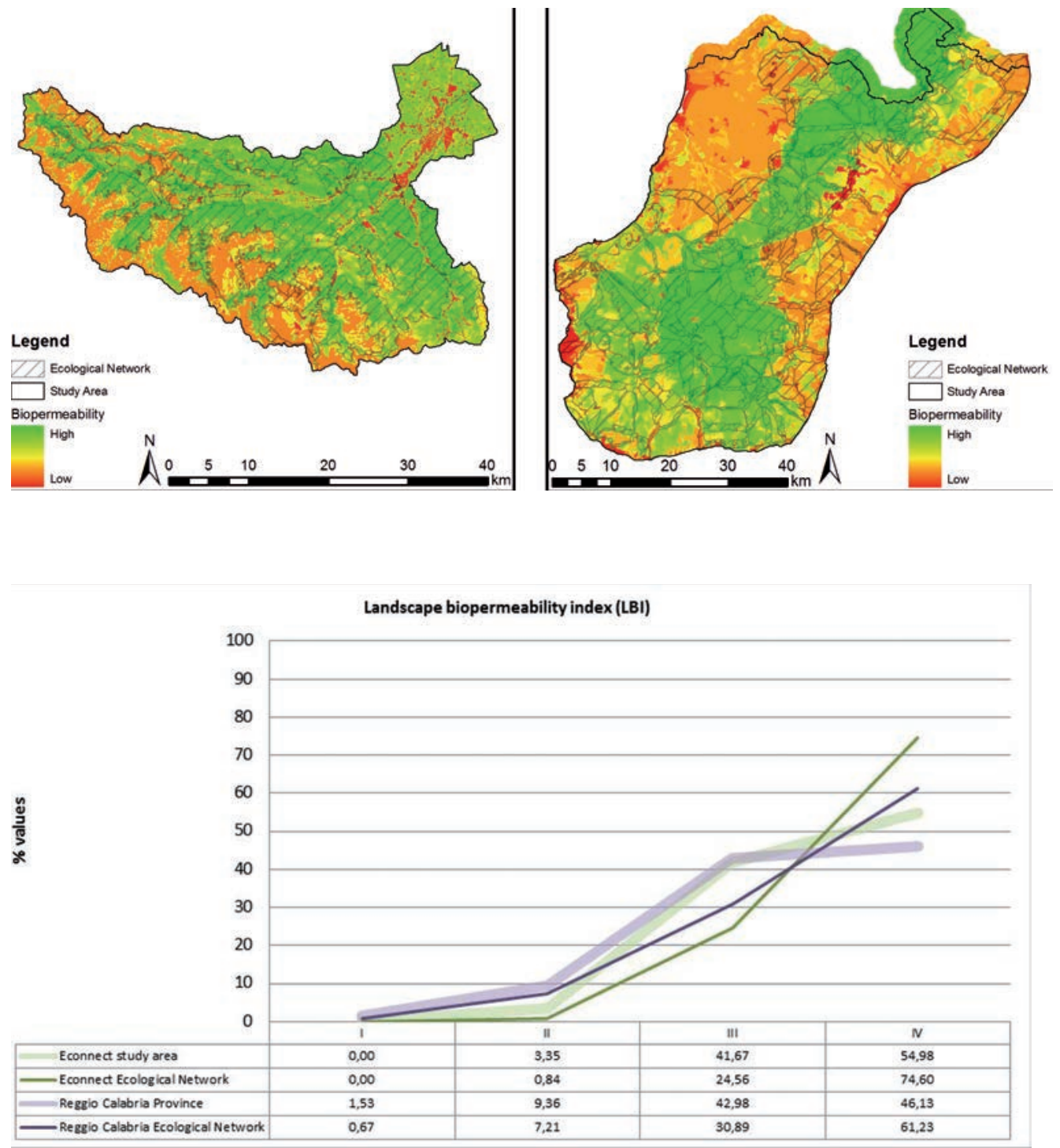

Figure 3. Landscape biopermeability index distribution map.
Figure 4. Graph of the distribution of biopermeability classes on the study areas and on the related ecological networks. 


\section{Environmental Sustainability Index (ESI)}

The Environmental Sustainability index (ESI) (Magoni, M. Steiner, 2001; Treu, Magoni, Steiner, \& Palazzo, 2005) is an indicator of the level of ecological stability of the landscape based on models of compartmental land management (Odum, 1983) that give the different land uses the capacity to perform different (or even conflicting) functions. As a result, a condition of sustainable development may be achieved through a balanced dimensional ratio and an effective interaction between the various land covers, which depends on the different pressure and regeneration processes they can carry out (Fichera et al., 2010).

Once the eigenvectors of pressure (AP, Anthropic Pressure) and regeneration (ER, Environmental Regeneration) matrices were calculated, ESI was calculated through the following passages:

- areas covered by the land uses were multiplied by the respective values of AP and ER;

- ESI was calculated as the ratio between the total equivalent area of regeneration $\left(\mathrm{VA}_{\text {regeneration }}\right)$ and the overall equivalent area $\left(\mathrm{VA}_{\text {regeneration }}+\mathrm{VA}_{\text {pressure }}\right)$, which were defined for each land use class (equivalent area is meant as the estimate of the equivalent area of
ER necessary to rebalance a unit of equivalent area of AP):

$$
E S I=V A_{\text {regeneration }} /\left(V A_{\text {regeneration }}+V A_{\text {pressure }} * \alpha\right)
$$

Where is the coefficient of ecological stability used to set the indicator (Table 2).

ESI values were associated to each land cover class for each study area and for the corresponding ecological networks (Figure 9). Surface values were grouped into three classes and made comparable through the calculation of their incidence rates (Figure 10).

Also in this case, the graph shows a marked difference in the index spatial distribution in the two study areas (second and third class) but a certain consistency in the trend of the values on the networks. This discrepancy is due to the higher incidence of agricultural areas (ESI average values) on the territory of the Province of Reggio Calabria and, as a consequence, to the higher proportional weight of forestry areas (high ESI values) on the ECONNECT study area.
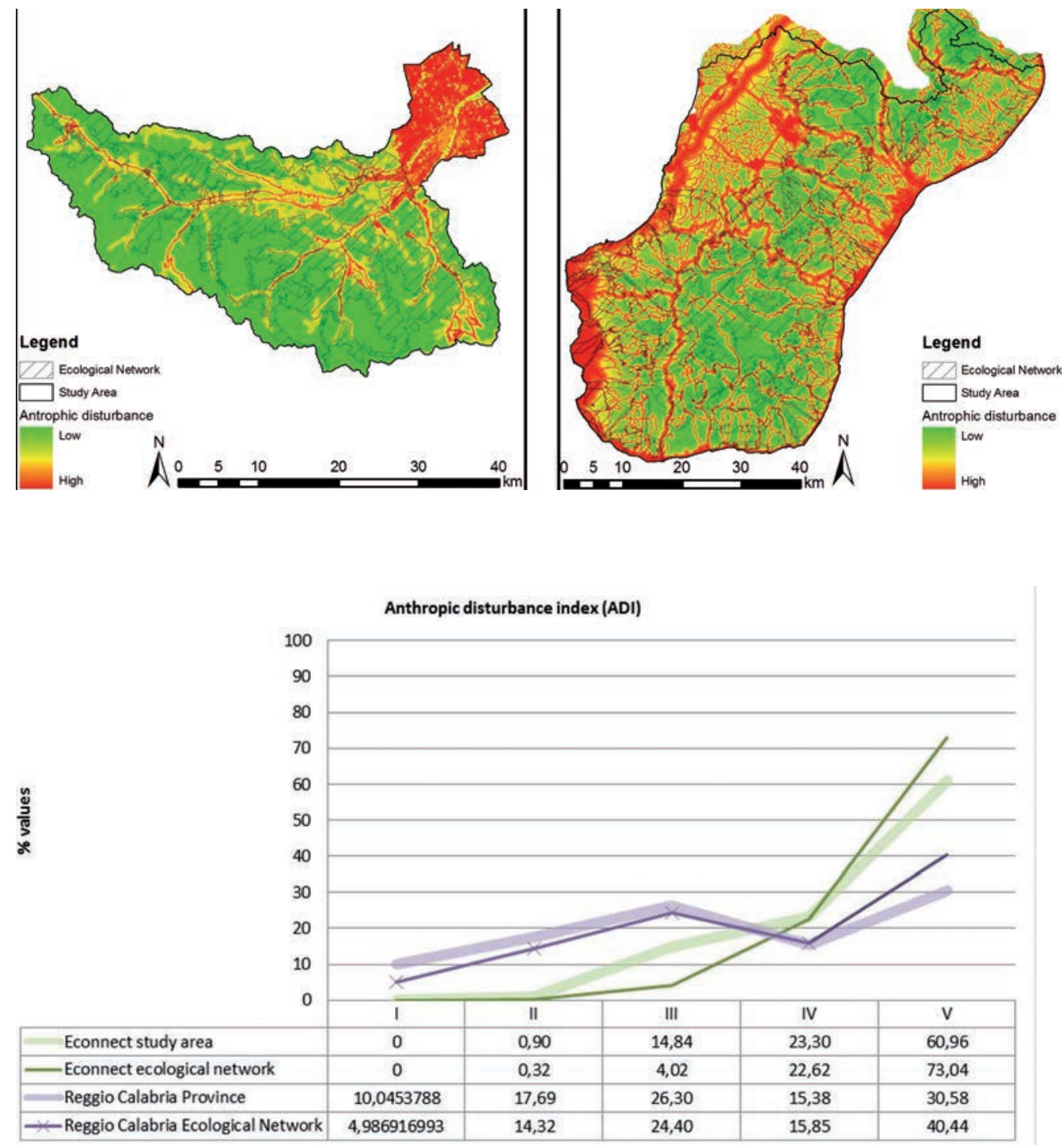

[page 496]
Figure 5. Anthropic disturbance index distribution map.
Figure 6. Graph of the distribution of anthropic disturbance classes on the study areas and on the corresponding ecological networks 
Table 2. Environmental Sustainability Index (ESI) values for each of the defined land cover classes

\begin{tabular}{lccc} 
Land cover classes & $\begin{array}{c}\text { Values of each land cover class } \\
\text { VA } \\
\text { Regeneration }\end{array}$ & $\begin{array}{c}\text { VA } \\
\text { Pressure }\end{array}$ & wSI \\
Forestry areas & 99738.81 & 6642.6046 & 0.9147 \\
Bush-lands & 20241.23 & 2412.16 & 0.85 \\
\hline Grasslands & 4164.68 & 541.46 & 0.84 \\
\hline Agro-forestry areas & 1126.29 & 262.27 & 0.75 \\
\hline Extensive arable lands and pastures & 3756.52 & 2186.11 & 0.55 \\
Complex cultivation patterns & 42675.04 & 38243.29 & 0.44 \\
\hline Intensive arable lands & 6598.74 & 12154.92 & 0.27 \\
\hline Discontinuous urban fabric & 164.83 & 1168.54 & 0.09 \\
\hline Continuous urban fabric & 659.40 & 7208.65 & 0.06 \\
Yards & 113.02 & 1808.41 & 0.04 \\
\hline
\end{tabular}
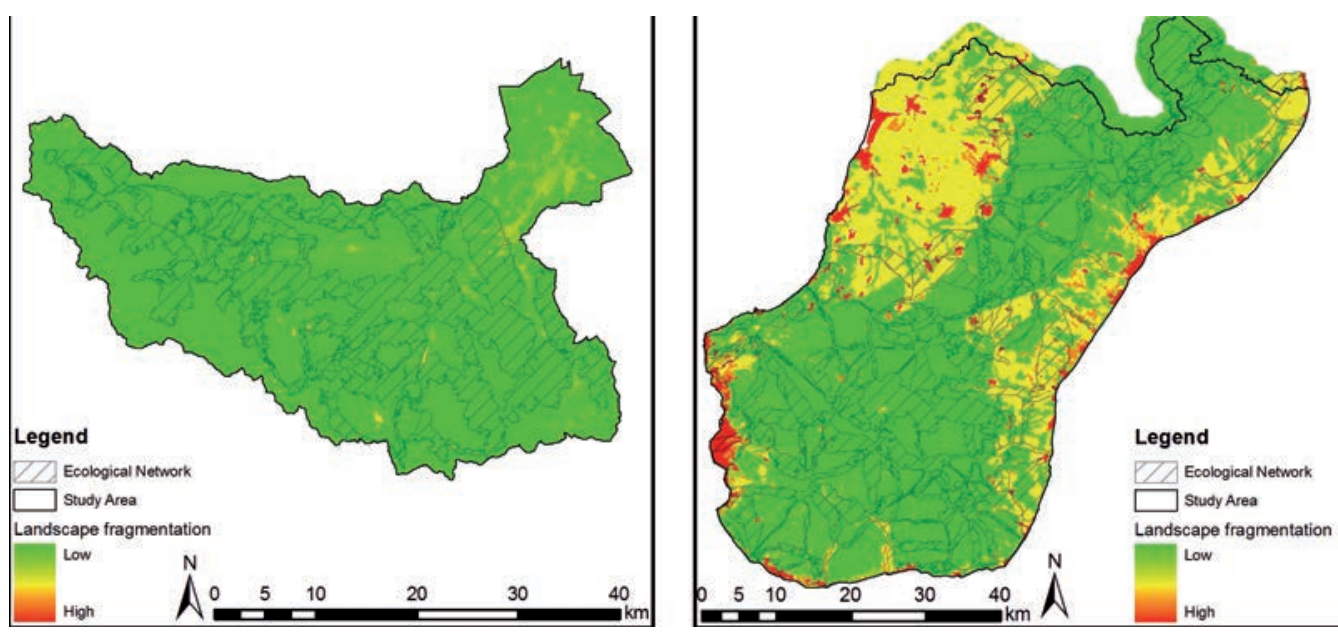

Figure 7. Landscape fragmentation index distribution map.

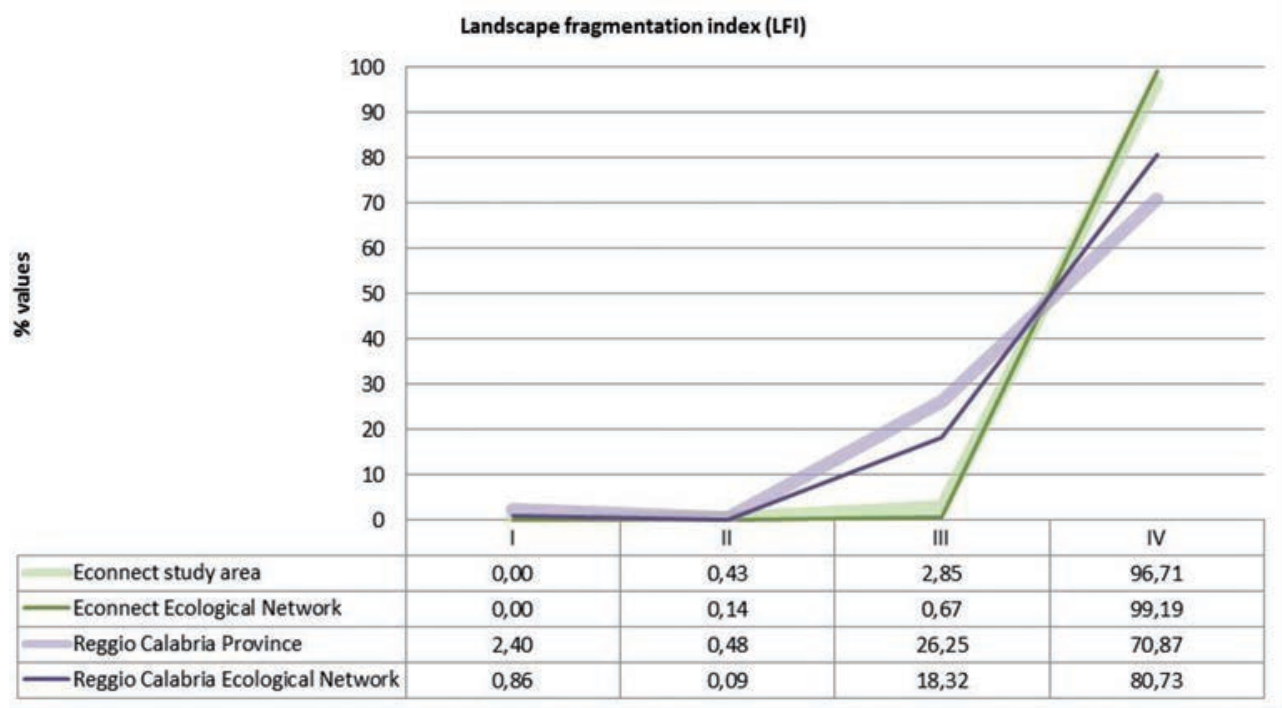

Figure 8. Graph of distribution of the landscape fragmentation classes on the study areas and on their ecological networks 


\section{Conclusions}

To curb the phenomena of territorial fragmentation is one of the objectives of a correct policy of environmental conservation. As a matter of fact, any treatment of the theme of natural conservation, which is linked to spatial planning based on the mere delimitation of areas and on forms of elementary protection, is anachronistic. The focus must shift from the site or the species to the ecosystem or the habitat so as not to be constrained by the concept of geographical or administrative border. In this new planning scenario, the terms "delimitation" and "zoning" are meant as "structuring of a permeable territorial fabric" able to interconnect the different natural areas as elements of a large system and to guarantee the regular internal dynamics of biological systems.

The model allowed obtaining the design of an ecological network that complies with the theoretical physiographic and functional aspects and with the fundamental characteristics of ecological networks (Bennet \& Wit, 2001; A. F. Bennett, 1999; G. Bennett \& Mulongoy, 2006). This resulted in an integrated approach to planning that may ensure ecological consistency and territorial multifunctionality (G.
Bennett \& Mulongoy, 2006). In other words, it would be a wide-ranging green infrastructure aimed at integrating the maintenance of ecological functionality and the real needs and potential expressions of the landscape (Lafortezza, Davies, Sanesi, \& Konijnendijk, 2013).

The comparison showed that, in order to effectively model core areas and corridors, the best research scale should be that of a large area (medium spatial scale). This parameter influences not only the applicative importance of results but also the design of networks. In fact, a large-scale application imposes the presence of cutting lines that directly depend on the imposed limits. The application of the model, with the same parameters but on different borders, generates different networks that are not significant at a local scale, though they still allow getting information on the quantity and on the location of high quality habitats for each species.

Particularly referring to the design of networks, in case of high ecological fragmentation, the model tends to generate small patches scattered on the territory. In this situation, corridors are oversized and play a dominant role within the network, thus making their precise analysis unavoidable for an interim validation of the network. When fragmentation is lower and characterized by large and evenly distributed patches, the model generates shorter corridors, since it can at most delimit the
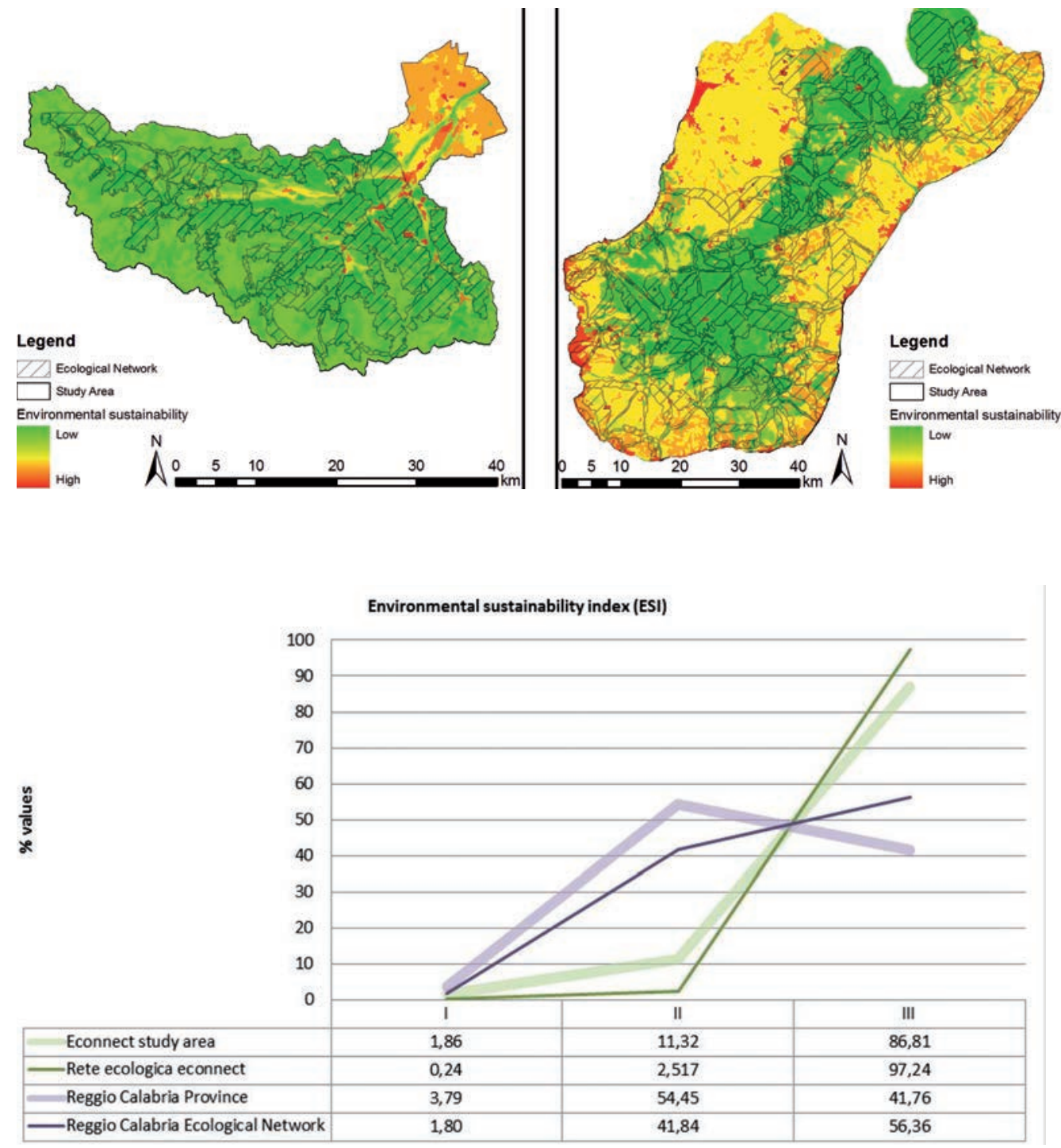

[page 498]
Figure 9. ESI index distribution map.

Figure 10. Graph of distribution of the environmental sustainability classes in the study areas and in the corresponding ecological networks. 
width of the lower-friction directrices, depending on the biological and ecological characteristics of the faunal species.

An important result is certainly the replicability of the model, which can be used again to integrate further species. Therefore, it proves to be a tool that may be normally used in a system of collection and organization of faunal data and information. Then, the creation of the integrated network must be seen as a result that allows making planning and programming choices able to meet requirements of synthesis and analysis.

Furthermore, the available faunal information for the ECONNECT project territory showed that the presence and location of the species investigated corresponded to the most fitting areas identified by the model. It also provided consistent data related to the clash between fauna and infrastructures.

The analysis carried out demonstrated that, thanks to its characteristics of synthesis, replicability and integrability, the model allows obtaining consistent and similar responses on territories that are orographically, structurally and biologically different.

\section{References}

APAT (2003). Management of the areas for ecological-functional connection. Guidelines and operating procedures for the adjustment of the instruments of spatial planning in relation to the construction of ecological networks at the local level. APAT manuals and guidelines.

Battisti, C., \& Luiselli, L. (2011). Selecting focal species in ecological network planning following an expert-based approach: Italian reptiles as a case study. Journal for Nature Conservation, 19(2), 126130. doi:10.1016/j.jnc.2010.10.001

Bennet, G., \& Wit, P. (2001). The Development and Application of Ecological Networks. A Review of Proposals, Plans and Programmes (p. 131). Amsterdam: AIDenvironment.

Bennett, G., \& Mulongoy, K. (2006). Review of experience with ecological networks, corridors and buffer zones (p. 100). Montreal: Secretariat of the Convention on Biological Diversity, Technical Series No. 23.

Boitani, L. (2000). National Ecological Network and biodiversity conservation. Parchi, 29, 66-74.

Boitani, L., Falcucci, A., Maiorano, L., \& Rondinini, C. (2007). Ecological networks as conceptual frameworks or operational tools in conservation. Conservation biology: the journal of the Society for Conservation Biology, 21(6), 1414-22. doi:10.1111/j.15231739.2007.00828.x

Bona, F., Badino, G., \& Isaia, M. (2006). Designing a "tailor-made" ecological network using geographical information systems. Ecological Research, 21(4), 605-610. doi:10.1007/s11284-006-0157$\mathrm{y}$

Drielsma, M., Ferrier, S., \& Manion, G. (2007). A raster-based technique for analysing habitat configuration: The cost-benefit approach. Ecological Modelling, 202(3-4), 324-332. doi:10.1016/j.ecolmodel.2006.10.016

EEA (European Environment Agency). (2000). CORINE land cover technical guide - Addendum 2000. (EEA (European Environment Agency), Ed.) (p. 105). Copenhagen.

ETC - European Territorial Cooperation. (2007). Alpine Space Programme. Retrieved from http://www.alpine-space.eu/

Fichera, C. R., Laudari, L., \& Modica, G. (2007). The implementation of an environmental connection matrix for the exploitation of marginal rural areas. The case study of the Tyrrhenian coast of Reggio Calabria. Multifunctionality and sustainable development of rural areas. Technological innovation and enhancement of typical marginal areas (p. 236). Reggio Calabria: Iiriti.

Fichera, C. R., Laudari, L., \& Modica, G. (2009a). A model for the structuring of ecological networks to support the landscape planning. The case of the province of Reggio Calabria. IX National Congress of the Italian Association of Agricultural Engineering "Research and innovation in engineering of agro-territorial biosystems". Ischia Porto: AIIA.

Fichera, C. R., Laudari, L., \& Modica, G. (2009b). Ecological networks as a key in sustainable landscape planning to solve landscape fragmentation. XXXIII CIOSTA CIGR V Conference on "Technology and management to ensure sustainable agriculture, agro-systems, forestry and safety" (Vol. 3, pp. 1707-1711). Reggio Calabria.

Fichera, C. R., Laudari, L., \& Modica, G. (2009c). A GIS for the definition of the ecological network in the Province of Reggio Calabria (Un GIS per la definizione della rete ecologica della Provincia di Reggio Calabria). XII ESRI Conference. Rome, Italy.

Fichera, C. R., Laudari, L., \& Modica, G. (2010). From the construction of an ecological network to the definition of an environmentally sustainable planning model for periurban space. XVII World Congress International Commission Of Agricultural And Biosystems Engineering (cigr). Quebec, Canada.

Fiduccia, A. (1998). GIS techniques for environmental planning. MondoGIS, 11.

Forman, R. T. T. (2000). Estimate of the Area Affected Ecologically by the Road System in the United States. Conservation Biology, 14(1), 31-35. doi:10.1046/j.1523-1739.2000.99299.x

Forman, R. T. T. (2003). Road Ecology: Science and Solutions (p. 481). Island Press.

Forman, R. T. T. (2008). Land Mosaics: The Ecology of Landscapes and Regions (p. 656). Cambridge, UK: Cambridge University Press.

Forman, R. T. T., \& Alexander, L. E. (1998). Roads and their major ecological effects. Annual Review of Ecology and Systematics, 29(1), 207-231. doi:10.1146/annurev.ecolsys.29.1.207

Franco, D. (2003). Sustainable landscapes and biodiversity: motives, objectives and opportunities for implementation of ecological networks (Paesaggi sostenibili e biodiversità: motivi, obiettivi ed opportunità di realizzazione delle reti ecologiche). Genio Rurale, $10,52-64$.

Godron, M., \& Forman, R. T. T. (1983). Landscape modification and changing ecological characteristics. In H. A. Mooney \& M. Godron (Eds.), Disturbance and ecosystems (pp. 12-28). Berlin: Springer Berlin Heidelberg. doi:10.1007/978-3-642-69137-9_2

Haber, W. (1993). Ökologische grundlagen des umweltschutzes. Bonn: Umweltschutz: Grundlagen und Praxis.

Harris, L. D. (1984). The fragmented forest; island biogeography theory and the preservation of biotic diversity (p. 211). Chicago, IL (USA): Univ. of Chicago Press.

Hobbs, R. J. (2002). Habitat Networks and Biological Conservation. In K. J. Gutzwiller (Ed.), Applying Landscape Ecology in Biological Conservation (pp. 150-170). New York, NY, USA: Springer. doi:10.1007/978-1-4613-0059-5_9

Jaeger, J. A. G. (2000). Landscape division , splitting index , and effective mesh size : new measures of landscape fragmentation, 115130 .

Jongman, R. H. G. (1995). Nature conservation planning in Europe: developing ecological networks. Landscape and urban planning, 32(3), 169-183. Retrieved from http:/www.sciencedirect.com/science/article/pii/0169204695001970

Jongman, R., \& Pungetti, G. (2004). Ecological networks and greenways: concept, design, implementation (p. 368). Cambridge, UK: Cambridge University Press.

Kunzl, M., Badura, M., Heinrichs, A.-K., Plassmann, G., Haller, R., \& 
Walzer, C. (2011). econnect Implementation \& Recommendations. Nursing Outlook (Vol. 58, p. 24). Innsbruck, Austria: STUDIA Universitätsbuchhandlung und -verlag.

Magoni, M. Steiner, F. (2001). The Environment in the Provincial Plan of Cremona, Italy. Environmental Management, 27(5), 639-654.

Metzger, J., \& Dècamps, H. (1997). The structural connectivity threshold: an hypothesis in conservation biology at the landscap scale, 18(1), 1-12.

Modica, G., Vizzari, M., Pollino, M., Fichera, C. R., Zoccali, P., \& Di Fazio, S. (2012). Spatio-temporal analysis of the urban-rural gradient structure: an application in a Mediterranean mountainous landscape (Serra San Bruno, Italy). Earth System Dynamics, 3(2), 263-279. doi:10.5194/esd-3-263-2012

Mortelliti, A., Amori, G., \& Boitani, L. (2010). The role of habitat quality in fragmented landscapes: a conceptual overview and prospectus for future research. Oecologia, 163(2), 535-47. doi:10.1007/s00442010-1623-3

Noss, R. F., \& Harris, L. D. (1986). Nodes, networks, and MUMs: Preserving diversity at all scales. Environmental Management, 10(3), 299-309. doi:10.1007/BF01867252

Odum, E. P. (1983). Basic ecology. (Saunders College Pub., Ed.) (p. 613). University of Michigan.

Opdam, P., Steingröver, E., \& Rooij, S. van. (2006). Ecological networks: A spatial concept for multi-actor planning of sustainable landscapes. Landscape and Urban Planning, 75(3-4), 322-332. doi:10.1016/j.landurbplan.2005.02.015

Pelorosso, R., Boccia, L., Amici, A., Tuscia, U., Federico, N., Lorenzo, P., \& Dipartimento, B. (2008). Simulating Brown hare ( Lepus europaeus Pallas ) dispersion : a tool for wildlife management of wide areas, 335-350.

Rientjes, S., \& Roumelioti, K. (2003). Support for ecological networks in
European nature conservation: an indicative social map. (D. Groels, Ed.) (European C., p. 55). Tilburg, Netherlands: European Centre for Nature Conservation.

Romano, B. (2000). Continuity and environmental reticularity, new protagonists of the territorial plan. International Conference "Ecological Networks - Local actions of territorial management for the conservation of the environment". Gargnano: Study center Valerio Giacomini.

Romano, B. (2003). Evaluation of urban fragmentation in the ecosystems. International conference on mountain environment and development (ICMED). Chengdu, Sichuan, Chima.

Romano, B. (2005). The indicators of ecological fragmentation in land use planning. Proceedings of the national conference "ecoregions and ecological networks: planning meets conservation. Roma: WWF - UPI.

Saunders, D. A., Hobbs, R. J., \& Margules, C. R. (1991). Biological Consequences of Ecosystem Fragmentation: A Review. Conservation Biology, 5(1), 18-32. doi:10.1111/j.15231739.1991.tb00384.x

Theobald, D. M. ., Norman, J. B. ., \& Sherburne, M. R. (2006). FunConn v1 User's Manual: ArcGIS tools for Functional Connectivity Modeling. (p. 51). Fort Collins, C0.: Natural Resource Ecology Lab, Colorado State University.

Treu, M. C., Magoni, M., Steiner, F., \& Palazzo, D. (2005). Sustainable landscape planning for Cremona , Italy, 47(2000).

Watts, K., Eycott, A. E., Handley, P., Ray, D., Humphrey, J. W., \& Quine, C. P. (2010). Targeting and evaluating biodiversity conservation action within fragmented landscapes: an approach based on generic focal species and least-cost networks. Landscape Ecology, 25(9), 1305-1318. doi:10.1007/s10980-010-9507-9. 